\title{
Frequency of Birth Defects and its Relationship to Parents Having Interfamily Marriages at a Tertiary Care Hospital
}

Tufail Soomro*1, Shiyam Sunder Tikmani ${ }^{2}$

${ }^{1}$ Department of Pediatrics, Ghulam Mohammad Mahar Medial College, Sukkur, Pakistan

${ }^{2}$ Aga Khan University, Department of Community Health Sciences, Karachi, Pakistan

*Corresponding author: Tufail Soomro, Department of Pediatrics, Ghulam Mohammad Mahar Medial College, Sukkur, Pakistan, Tel: +923337279661; E-mail: drtufailsoomro@hotmail.com

Received date: July 26, 2016, Accepted date: August 30, 2016, Published date: August 31, 2016

Copyright: (c) 2016 Soomro T, et al. This is an open-access article distributed under the terms of the Creative Commons Attribution License, which permits unrestricted use, distribution, and reproduction in any medium, provided the original author and source are credited.

\begin{abstract}
Background: Inter family cousin marriages carries a risk of increased birth defects. The exact contribution of interfamily to birth defects risk is controversial. The aims of this study were to determine the frequency of birth defects in in relation to interfamily or outside family marriages.

Methods: This cross sectional study was conducted in the Civil hospital Sukkur from $9^{\text {th }}$ November 2013 to $13^{\text {th }}$ December 2015. Mothers giving birth to babies married in interfamily or outside family with their consent obtained were included in the study. Mothers not giving consent for study and having any known major illnesses were excluded from this study. Data was analyzed using SPSS version 21.0.

Results: The mean age of enrolled participants is $26.72 \pm 7.07$ years, the mean years of marriage was $5.95 \pm 6$ years and $49.4 \%$ were residents of urban area. Overall $89.9 \%$ were Muslims, $8.4 \%$ Christians and $2.8 \%$ Hindus, $60.7 \%$ infant had gestational age of $<37$ weeks. Overall $11.4 \%$ of newborns have congenital malformations. Frequency of congenital malformations among interfamily marriages was $15.6 \%$ compared to outside family marriages accounted for $3.7 \%$ cases $(p=0.021)$.
\end{abstract}

Conclusion: It was concluded from this study that congenital malformations are common among participants of interfamily marriages.

Keywords: Congenital malformations; Interfamily marriages; Outside family marriages

\section{Introduction}

Birth defects are presenting as gross physical, hidden inside body as well as defects at cellular level like enzymes that present at birth resulted in physical and /or mental disabilities [1]. The underlying etiology of birth defects is multifactorial which include genetic factors, maternal age, and intake of drugs, exposure to teratogenic agents or radiation, maternal illness/infection, smoking, interfamily and alcohol consumption. A birth defect can be single or multiple, live threatening or non-life threatening [2]. In developed countries, the proportion of birth defects is rising due to good infection control and low prevalence of under nutrition $[3,4]$. The reported prevalence of birth defects varies in different geographic areas, ethnicities and populations [5]. In Pakistan, about $6 \%$ to $9 \%$ perinatal deaths are attributed to birth defects [6]. Common birth defects are neural tube defects, congenital heart diseases, gastrointestinal defects, genitourinary defects, face defects, musculoskeletal defects and ear anomalies [7] Long-term survival of children with birth defects is significantly lower than normal children [8].

Inter-family cousin marriages carry a risk of increased birth defects. Most of the published literature has reported the effect of interfamily marriages on birth defects as causative. However, risk factors like gestational diabetes mellitus (GDM), parity, socioeconomic strata, maternal age and literacy, intake of the teratogenic drug in the first trimester of pregnancy, and peri-conception chemical exposure. Scientist around the world has different schools of thoughts one school of thought believes that consanguinity produces specific types of birth defects [9-11] and others believe that the contribution of consanguinity to the etiology of major birth defects has been overestimated [12].

Interfamily marriages between first or second cousins are very common in Sindh, Pakistan [10], where interfamilial unions account for $20 \%$ to $50 \%$ of all marriages. First and second cousins marriages are favored by most of the families. Another study reported that rate of birth defects by interfamily marriages was $7 \%$ whereas in outside family marriages it was recorded to be $2 \%$ [13].

The exact contribution of interfamily to birth defects risk is controversial because we lack reliable local data and many studies did not take account of confounding factors and interactions with other exposures at the time of analysis. Accordingly, we would like to conduct this study because it addresses the issues related to birth defects and shows practical/public health relevance in societies with interfamily marriages vs. outside family marriages.

Interfamily first and second cousins marriages are prevalent in most of the families of Sindh because of social, cultural and other reasons. The exact contribution of interfamily marriages to birth defects risk is controversial because we lack reliable data. The present study addressed the frequency of birth defects in interfamily vs. outside family marriages. 
Citation: Soomro T, Tikmani SS (2016) Frequency of Birth Defects and its Relationship to Parents Having Interfamily Marriages at a Tertiary Care Hospital. J Gen Pract (Los Angel) 4: 265. doi:10.4172/2329-9126.1000265

Page 2 of 4

\section{Material and Methods}

This was a cross sectional study conducted in Civil Hospital Sukkur from $9^{\text {th }}$ November 2013 to $13^{\text {th }}$ December 2015. Newborn delivered in the Civil Hospital Sukkur were screened for gross congenital malformations. Infants were enrolled after taking informed consent from mother. Mothers refused to participate were excluded from the study. Detailed history was taken with emphasis on age of mother, gestational age, duration of marriage, inter-family marriage and antenatal detection of congenital defect. Detailed physical examination of newborn was carried out. Anthropometric measurements (weight, length and fronto-occipital circumference) were also taken. Two readings were taken and average was taken for the analysis. Examination of eye, mouth, ear, facial features, cardiovascular system, gastrointestinal system, musculoskeletal system, abdomen, chest and genitourinary system was done. The findings were recorded in a proforma.

\section{Statistical analysis}

Sample size was collected through non-probability purposive sampling. A total of 450 mothers were included in this study. Data was analyzed by using SPSS 21.0 (IBM, incorporation, USA). Frequencies and percentages were presented for categorical variables like gender, interfamily marriage and congenital malformations. Mean \pm SD was reported for continuous variables. Chi square test or Fisher exact test was applied for comparison of categorical and student's t-test was applied for comparison of continuous variables. P-value of $<0.05$ was considered significant.

\section{Results}

A total of 534 patients were enrolled in this study during study period (Figure 1).

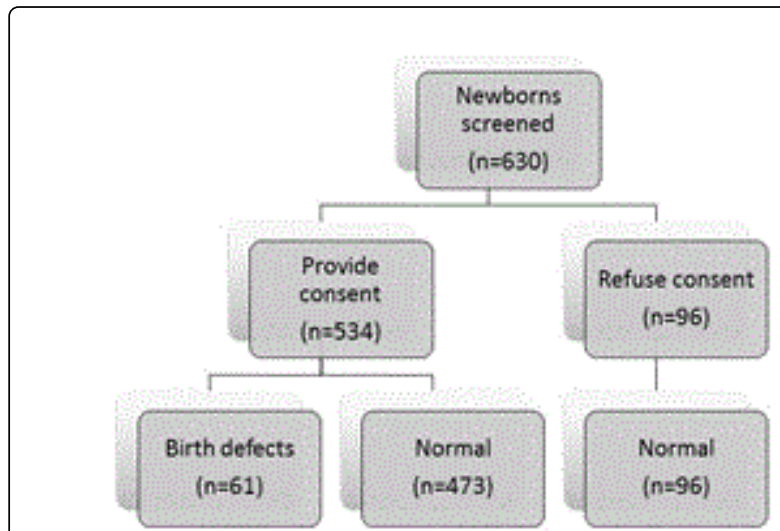

Figure 1: Flow chart.

The mean age of enrolled participants is $26.72 \pm 7.07$ years, and $55.2 \%$ of mothers were $>30$ years of age, the mean years of marriage was $5.95 \pm 6$ years. Overall $49.4 \%$ women were residing in urban area and $50.6 \%$ in rural areas. Majority of women were Sindhi speaking as mother tongue accounting for $45.5 \%$ cases.

Approximately, 89\% women were Muslims, 8\% Christians and 3\% Hindus, $60 \%$ women had gestational age of $<37$ weeks, $68.4 \%$ had interfamily marriages. Overall $11.5 \%$ of newborns have congenital malformations.

Comparison of baseline characteristics is summarized in Table 1 and type of malformation is summarized in Figure 2.

\begin{tabular}{|c|c|c|c|c|c|}
\hline \multirow{2}{*}{\multicolumn{2}{|c|}{ Variables }} & \multicolumn{2}{|c|}{ Birth defects } & \multirow{3}{*}{$\begin{array}{l}\begin{array}{l}\text { Total } \\
(\mathbf{n}=534)\end{array} \\
295(55 \%)\end{array}$} & \multirow{2}{*}{ P-value } \\
\hline & & \multirow{2}{*}{$\begin{array}{l}\text { Yes }(n=61) \\
24(39 \%)\end{array}$} & \multirow{2}{*}{$\begin{array}{l}\text { No }(n=473) \\
271(57 \%)\end{array}$} & & \\
\hline \multirow{2}{*}{ Age of mother } & $<30$ years & & & & \multirow{2}{*}{0.006} \\
\hline & $\geq 30$ years & $37(61 \%)$ & $202(43 \%)$ & $239(45 \%)$ & \\
\hline \multirow{2}{*}{ Years of marriage } & $<5$ years & $22(36 \%)$ & $214(45 \%)$ & $236(44 \%)$ & \multirow{2}{*}{0.11} \\
\hline & $\geq 5$ years & $39(64 \%)$ & $259(55 \%)$ & $298(56 \%)$ & \\
\hline \multirow{2}{*}{ Residency } & Urban & $32(53 \%)$ & $232(49 \%)$ & $264(49 \%)$ & \multirow{2}{*}{0.357} \\
\hline & Rural & $29(46 \%)$ & $241(51 \%)$ & $270(51 \%)$ & \\
\hline \multirow{4}{*}{ Ethnicity } & Sindhi & $27(44 \%)$ & $216(46 \%)$ & $243(46 \%)$ & \multirow{4}{*}{0.367} \\
\hline & Mohajir & $6(10 \%)$ & $46(10 \%)$ & $52(10 \%)$ & \\
\hline & Pathan & $28(46 \%)$ & $190(40 \%)$ & $218(41 \%)$ & \\
\hline & Punjabi & $0(0.0 \%)$ & $21(4 \%)$ & $21(4 \%)$ & \\
\hline \multirow{3}{*}{ Religion } & Islam & $49(80 \%)$ & $425(90 \%)$ & $474(89 \%)$ & \multirow{3}{*}{0.016} \\
\hline & Christians & $8(13 \%)$ & $37(8 \%)$ & $45(8 \%)$ & \\
\hline & Hinduism & $4(7 \%)$ & $11(2 \%)$ & $15(3 \%)$ & \\
\hline
\end{tabular}


Page 3 of 4

\begin{tabular}{|l|l|l|l|l|l|}
\hline \multirow{2}{*}{ Gestational age } & $<37$ weeks & $50(82 \%)$ & $274(58 \%)$ & $324(61 \%)$ & $<0.001$ \\
\cline { 2 - 6 } & $\geq 37$ weeks & $11(18 \%)$ & $199(42 \%)$ & $210(39 \%)$ & 0.02 \\
\hline \multirow{2}{*}{ Relation } & Inter-family marriage & $44(72 \%)$ & $321(68 \%)$ & $365(68 \%)$ & $169(32 \%)$ \\
\cline { 2 - 6 } & Outside family marriage & $17(28 \%)$ & $152(32 \%)$ & $68(64 \%)$ & $<0.001$ \\
\hline \multirow{2}{*}{ Type } & One anomaly & $23(38 \%)$ & $44(100.0 \%)$ & $37(35 \%)$ & \\
\cline { 2 - 6 } & Multiple anomaly & $37(61 \%)$ & $0(0.0 \%)$ & & \multirow{2}{*}{0} \\
\hline
\end{tabular}

Table 1: Baseline characteristics of enrolled participants by outcome.

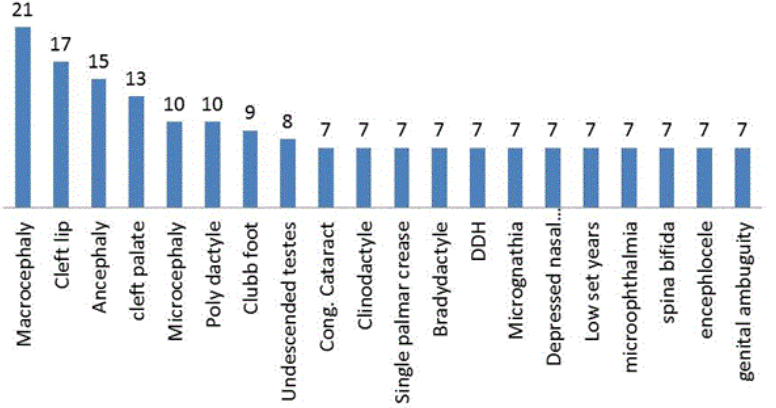

Figure 2: Frequencies of congenital malformations.

\section{Discussion}

Birth of abnormal child is a stressful situation for mother as well as for society. About 8 million children are born each year with congenital abnormalities, out of which 3.3 million die before the age of five while 3.2 million survivors suffers from severe mental or physical disability [14]. Although it is a major global concern but advancing technology and early antenatal diagnosis of birth defects has altered the trends in birth prevalence of the congenital abnormalities [15].

Worldwide, the prevalence rates of all genetic birth defects combined range from a high of 82/1,000 live births in low income regions to a low of 39.7/1,000 live births in high income regions [16]. These malformations have multi-factorial etiologies and $40 \%$ of cases are idiopathic but there is an impression that they are more prevalent in populations with consanguineous marriages [17].

Despite amazing advances in science and technology, detection of causes of congenital malformation still remain obscure in most of the cases and only few identifiable factors led the scientist to rethink the situation which is global burden. The epidemiological survey of pattern and prevalence of congenital anomalies not only helps in understanding the frequency of malformations in specific area but also contribute to the general knowledge about the predisposing factors and different patterns of birth defects.

In the tropics, malnutrition and infections are main causes of infant morbidity and mortality while in the temperate zones, cancer, accidents and congenital abnormalities are the key causes of infant morbidity and mortality [18]. Prevalent studies of congenital anomalies are useful to establish baseline rates, to document changes over time and to identify clues to etiology. They are also important for health services planning and evaluating antenatal screening in populations with high risk. The study is also important as it may help to raise the awareness of surgical Pediatric intervention and to emphasize the loss of babies with congenital abnormalities. In this study the frequency of congenital malformation was $11.5 \%$ of them $50 \%$ had CNS malformations followed by $20 \%$ had cleft lip and palate, $10 \%$ each GI, musculoskeletal and ear, nose \& throat malformations.

The commonest anomaly detected in the study was the involvement of central nervous system. In a study it was revealed that alimentary tract, nervous system and cardiovascular system are the most commonly affected parts in descending order of frequency [19]. In accordance with other studies [20,21]. Neural tube defects (NTD) were the commonest anomaly found in this study accounting for $46.67 \%$ of cases. Consanguinity is considered a controversial association with congenital malformations (CMs). Increased incidence of $\mathrm{CM}$ in consanguineous couples is due to homozygous expression of recessive genes inherited from common ancestors [22]. The current study found $\mathrm{CMs}$ to be more common in consanguineous parents than nonconsanguineous which was in accordance with an earlier study (61.3\%) [23]. Another study also reported that CMs were 3.5 times more common in consanguineous than non-consanguineous marriages. This association is also supported by another study $[23,24]$.

In this study we found that $64 \%$ had interfamily marriages and the frequency of congenital malformations is common among interfamily marriages compared to marriages outside families $(p=0.021)$. In a study, it was reported that cousin marriages with $1^{\text {st }}$ degree cousin accounted for $83.33 \%$. Among interfamily marriage people, $15.6 \%$ had congenital malformations. In a study, consanguinity was accounted for $22 \%$ cases of congenital malformations.

There are some limitations to this study. Chromosomal analysis and Viral infections markers (TORCH) were not conducted in this study due to high cost of these tests which further add burden to the patient so only symptomatology of viral infections were asked to determine the risk in particular patient. In this study we also have not compared risk factors in controls so in future we will conduct study to determine the relative risk of each risk factor with congenital anomalies. Non probability sampling may lead to sampling bias and since sample is not impartially chosen it may not representative of population. Hence the external validity of this study is low. One more limitation, this hospital mostly serves the rural population, where most of the parents left against medical advice in case of anomalies due to culture reason. Parent are thinking that infants with congenital malformation can be treated by spiritual healers and hence often not come into medical attention especially if infants born at night. 


\section{Conclusion}

In conclusion, Neural tube defect is identified as major congenital abnormality in this community and consangious relationship being the biggest risk factor associated with it. Knowledge of incidence and pattern of CMs are important to plan preventive strategies at different levels by healthcare providers. Consanguineous marriages with first degree cousin and maternal relationship identified as major contributor and risk for congenital anomalies so discouraging intermarriages, and early termination of pregnancies in fatal cases will definitely reduce birth defects in community. In future large study will be required for genetic association to see family trends in this population and viral marker till that time consanguineous marriages will be considered as major risk factor in this population for increased risk of congenital malformation especially neural tube defect. It is therefore recommended that general awareness should be created regarding peri-conceptional use of folic acid use. Since most of the women presented during late pregnancy, it is important that antenatal care should be emphasized and it should be improved to detect and manage congenital anomalies in time.

\section{References}

1. Boygle CA, Cordero JF (2005) Birth Defects and Disabilities: A Public Health Issue for the 21st Century. Am J Public Health 95: 1884-1846.

2. Obu HA, Chinawa JM, Uleanya ND, Adimora GN, Obi IE (2012) Congenital malformations among newborns admitted in the neonatal unit of a tertiary hospital. BMC Res Notes 5: 177.

3. Qazi G (2010) Relationship of selected prenatal factors to pregnancy outcome and congenital anomalies. J Ayub Med Coll 22: 41-45.

4. Agha MM, Williams JI, Marrett L, To T, Dodds L (2006) Determinants of survival in children with congenital abnormalities: a long-term population-based cohort study. Birth Defects Res A Clin Mol Teratol 76: 46-54.

5. Kucik JE, Alverson CJ, Gilboa SM, Correa A (2012) Racial/ ethnicvariations in the prevalence of selected major birth defects, 1994-2005. Public Health Rep 127: 52-61.

6. Korejo R, Bhutta S, Noorani KH, Bhutta ZA (2007) An audit andtrends of perinatal mortality at the Jinnah PostgraduateMedical Centre, Karachi. J Pak Med Assoc 57: 168-171.

7. Rehman A, Fatima S, Soomro N (2006) Frequency of congenitalanomalies and associated maternal risk factors in the lowersocioeconomic groups. Pak J Surg 22: 169-173.

8. Ambe JP, Madziga AG, Akpede GO, Mava Y (2010) Pattern andoutcome of congenital malformations in newborn babies ina Nigerian teaching hospital. West Afr J Med 29: 24-29.

9. Parveen F, Tayyub S (2007) Frequency and pattern of congenital anomalies in the newborn and associated maternal risk factors. J Col Physician Surg Pak 17: 340-343.
10. Khan AA, Khattak TA, Shah SHA, Roshan E, Haq AU (2012) Pattern of Congenital Anomalies in the Newborn. J Rawalpindi Med Coll 16: 1-3.

11. Saidan MA, Ammari AN, Al Hashem AM, Al Rakaf MS, Shoukri MM, et al. (2015) Effect of Consanguinity on Birth Defects in Saudi Women: Results from a Nested Case-Control Study. Birth Defects Res A Clin Mol Teratol 103: 100-104.

12. Bittles A (2001) Consanguinity and its relevance to clinical genetics. Clin Genet 60: 89-98.

13. Mosayebi Z, Movahedian AH (2007) Pattern of congenital malformations in consanguineous versus nonconguineous marriages in Kashan, Islamic Republic of Iran. La Revue de Santé de la Mediterranee Oriental 13: 4.

14. Shaw GM, Wasserman CR, Lammer EJ, O'Malley CD, Murray JC, et al. (1996) Orofacial clefts, parental cigarette smoking, and transforming growth factor-alpha gene variants. Am J Hum Genet 58: 551-561.

15. George TM, Fagan LH (2005) Adult tethered cord syndrome in patients with postrepair myelomeningocele: an evidence-based outcome study. J Neurosurg 102: 150-156.

16. Marazita ML (2007) Subclinical features in non-syndromic cleft lip with or without cleft palate $(\mathrm{CL} / \mathrm{P})$ : review of the evidence that subepithelial orbicularis oris muscle defects are part of an expanded phenotype for CL/P. Orthod Craniofac Res 10: 82-87.

17. Rogers CR, Weinberg SM, Smith TD, Deleyiannis FW, Mooney MP, et al. (2008) Anatomical basis for apparent subepithelial cleft lip: a histological and ultrasonographic survey of the orbicularis oris muscle. Cleft Palate Craniofac J 45: 518-524.

18. Suzuki S, Marazita ML, Cooper ME, Cooper ME, Miwa N, et al. (2009) Mutations in BMP4 are associated with subepithelial, microform, and overt cleft lip. Am J Hum Genet 84: 406-411.

19. Jentink J, Dolk H, Loane MA, Morris JK, Wellesley D, et al. (2010) Intrauterine exposure to carbamazepine and specific congenital malformations: systematic review and case-control study. BMJ 341: c6581.

20. McDonald S, Hewer LCD, Nunez DA (2008) Grommets (ventilation tubes) for recurrent acute otitis media in children. Cochrane Database Syst Rev CD004741.

21. Mattsson S, Gladh G (2005) Children with meningomyelocele become adults. Lakartidningen 102: 2566-2570.

22. MMWR (2005) Use of dietary supplements containing folic acid among women of childbearing age-United States. Morb Mortal Wkly Rep 54: 955-958.

23. Lidral AC, Moreno LM (2005) Progress toward discerning the genetics of cleft lip. Curr Opin Pediatr 17: 731-739.

24. Vieira AR, Avila JR, Daack-Hirsch S, Dragan E, Félix TM, et al. (2005) Medical sequencing of candidate genes for nonsyndromic cleft lip and palate. PLoS Genet 1: e64. 